\title{
Effect of Building Height on Microstructure and Mechanical Properties of Big-Sized Ti-6Al-4V Plate Fabricated by Electron Beam Melting
}

\author{
Pan Wang ${ }^{a}$, Mui Ling Sharon Nai ${ }^{b}$, Wai Jack Sin ${ }^{c}$ and Jun Wei ${ }^{d}$ \\ Singapore Institute of Manufacturing Technology, 71 Nanyang Drive, 638075, Singapore
}

\begin{abstract}
Electron beam melting (EBM) is a layer by layer additive manufacturing technology, which has the capability of producing near-net shaped parts with complex geometries. It is also suitable for handling high melting point and reactive metallic materials, such as $\mathrm{Ti}$ alloy, which is widely used in the aerospace and biomedical applications. The present study focused on the relationship between the microstructure and mechanical properties of big-sized Ti-6Al-4V parts. A plate $(6 \mathrm{~mm} \times 180 \mathrm{~mm} \times 372 \mathrm{~mm})$ was additively manufactured by EBM. The microstructure evolution and variation of mechanical properties were investigated by using the $\mathrm{x}$-ray diffraction, optical microscope, scanning electron microscope and tensile test. The results revealed that with an increasing in the build height, there was a variation in the microstructure and the mechanical properties of the build plate. Although only $\alpha$ phase and a relatively small fraction of $\beta$ phase were detected in both the bottom and top specimens of the build plate, yield strength and ultimate tensile strength decreased with an increase of build height. This was attributed to the increase of $\alpha$ lath width which was caused by the different thermal histories along the build height of the plate.
\end{abstract}

\section{Introduction}

The traditional manufacturing technology, such as casting, forging, rolling, etc., though has fuelled the industrial revolution in the past decades, has its inherent limitations which are challenging to avoid. Additive manufacturing (AM) technologies aid to overcome some of the limitations, such as shortening the design to product time and reducing the process steps involved. Moreover, AM technologies have exhibited promising applications in high value added industries [1-5]. Electron beam melting (EBM) is one of the layer-by-layer AM techniques, which has the capability of producing near-net shaped parts with complex geometries. Furthermore, due to its vacuum controlled process and high energy electron beam, EBM can be used to process high melting point and reactive metallic materials. Therefore, it is suitable for fabricating Ti alloy parts for the aerospace and biomedical applications [6,7].

In comparison with their cast or wrought counterparts, the microstructure of EBM printed is drastically different due to the layer-by-layer fusion step which introduces rapid thermal cycles. Moreover, the previous layers experience a thermal history during printing and this further introduces a different thermal history for each subsequent layer. In order to ensure the use of these printed parts in structural applications, their mechanical properties must be characterized. To date, several researchers have focused on understanding the microstructure and mechanical properties of Co-Cr-based alloys [8], Ti alloys [7,9,10] and
Ni-based alloys [11] fabricated by the EBM technology. Although these results exhibited excellent mechanical properties, the investigations only focused on small build samples and/or parts with a short build height. However, for industry applications, in particular, aerospace applications, a big-sized part with complex shape is of actual industry need.

Accordingly, in the present study, the effect of build height on the microstructure and mechanical properties of a big-sized plate was investigated. To the best of our knowledge, no related study has been published to correlate the microstructure and properties of big-sized parts fabricated using the EBM process. Researchers have only reported the microstructure and mechanical properties along building orientation by using small samples and/or parts $[6,12,13]$. One of the reasons could be attributed to the use of much more powder in the building of a large/high build part. Hence, the present study focuses on bridging this research gap to better understand the microstructure-properties relationship of big-sized plates printed using the EBM process.

\section{Experimental Procedure}

Arcam A2X EBM system with a build envelope of $200 \mathrm{~mm} \times 200 \mathrm{~mm} \times 380 \mathrm{~mm}$ was used (Fig. 1a) to fabricate a Ti-alloy plate $(6 \mathrm{~mm} \times 180 \mathrm{~mm} \times 372 \mathrm{~mm})$ centered on a $210 \mathrm{~mm} \times 210 \mathrm{~mm}$ stainless steel start plate (Fig.1b). The

awangp@SIMTech.a-star.edu.sg, ${ }^{\mathrm{b}} \mathrm{mlnai} @$ SIMTech.a-star.edu.sg,

csinwj@SIMTech.a-star.edu.sg, djwei@SIMTech.a-star.edu.sg 
pre-alloyed $\mathrm{Ti}-6 \mathrm{Al}-4 \mathrm{~V}$ virgin powder with a nominal composition

of

Ti-6Al-4V-0.03C-0.1Fe-0.15O-0.01N-0.003H was used in the present study.
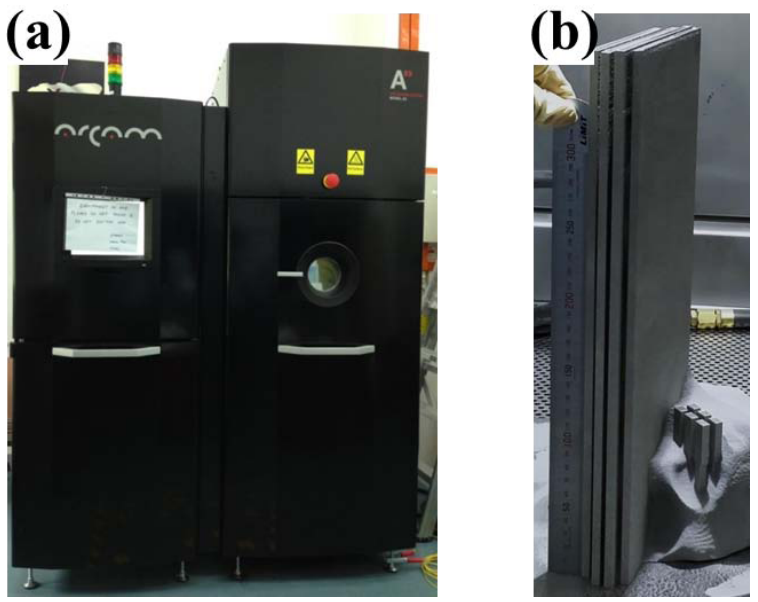

Fig. 1 Photos of the (a) Arcam A2X EBM system installed at the Singpore Institute of Manufactruing Technology and (b) as-printed Ti-6Al-4V plates.

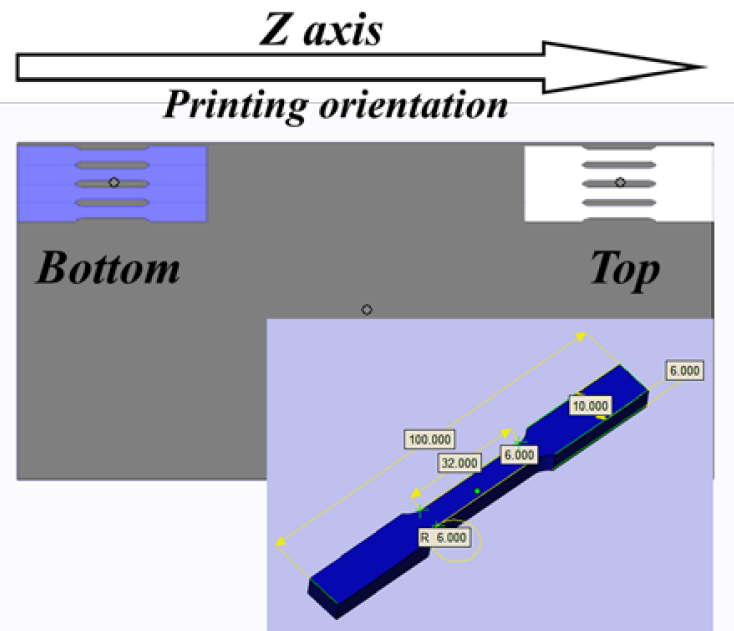

Fig. 2 Schematic illustration of specimens cut from the as-printed Ti-6Al-4V plate.

In order to investigate the effect of build height on the microstructure and mechanical properties, two groups of specimens along the build orientation were taken from the bottom-most and top-most sections of the plate respectively for evaluation (Fig. 2). Before the tensile test, the surface layer of the tensile specimens was removed by plunge grinding. The tensile test was conducted at room temperature in air, at an initial strain rate of $3.3 \times 10^{-4} \mathrm{~s}^{-1}$, using the Instron 4505 universal tensile testing machine with a load cell capability of $100 \mathrm{kN}$. The dimensions of the tensile specimens were illustrated in the inset of Fig. 2. In addition, an extensometer was applied to measure the strain. More than three specimens were tested under each condition and their yield strength (YS), ultimate tensile strength (UTS), elongation and Young's modulus were determined. The phases present in the specimens were characterized using the X-ray diffraction (XRD), at room temperature with $\mathrm{Cu} \mathrm{K} \mathrm{K}_{\alpha}$ radiation operated at $40 \mathrm{kV}$ and 40 $\mathrm{mA}$. Microstructural analysis was conducted using an optical microscope (OM). For the OM observation, the polished specimens were etched in a Kroll's reagent. Scanning electron microscope (SEM) was also used to observe the fracture surface after tensile test.

\section{Results and Discussion}

For Ti alloys, the present of phases and their distributions strongly influenced the samples' resultant mechancial properties [9,14-16]. Therefore, the micorstructures of both bottom and top specimens were measured by XRD and OM. Fig. 3 shows the XRD patterns of the as-printed Ti-6Al-4V plate.

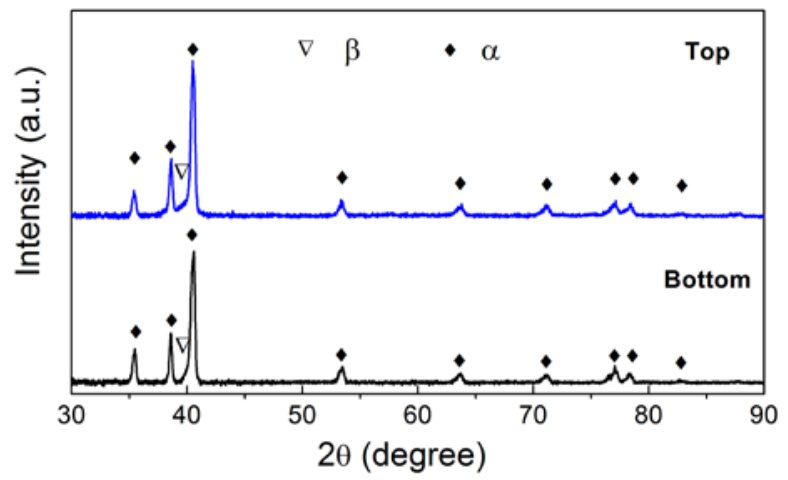

Fig. 3 XRD patterns of the as-pinted Ti-6Al-4V specimens.

The results exhibited that the phases present in the specimens are independent of their build height. Both bottom and top specimens contained only $\alpha$ phase and a relatively small fraction of $\beta$ phase. This is in agreement with the previous studies that no $\alpha^{\prime}$ phase was observed because of high preheating temperature and relatively big thermal mass resulting in a long exposure at the elevated temperature $[6,9,12,13]$. Although $\alpha$ phase was also observed in some small samples with thin wall [7] or on the top surface of short samples $(1 \mathrm{~mm})$ [9] due to the fast cooling speed without enough exposure in the elevated temperature. Fig. 4 shows the optical micrographs of the as-printed Ti-6Al-4V plate. In agreement with the XRD results, no martensitic structure was observed and only $\alpha$ phase and $\beta$ phase were observed. Furthermore, typical columnar structure was observed both bottom and top specimens. However, it was observed that the $\alpha$ lath width increased with an increase of build height and this will affect the mechanical properties [9]. Sun et al. [8] reported a gradient microstructure in the $\mathrm{Co}-\mathrm{Cr}$ alloy fabricated by EBM and this is due to the effect of different thermal histories on the different build height. The increase of $\alpha$ lath width was attributed to the faster cooling speed on the bottom specimen, as compared to that of the top specimen. 

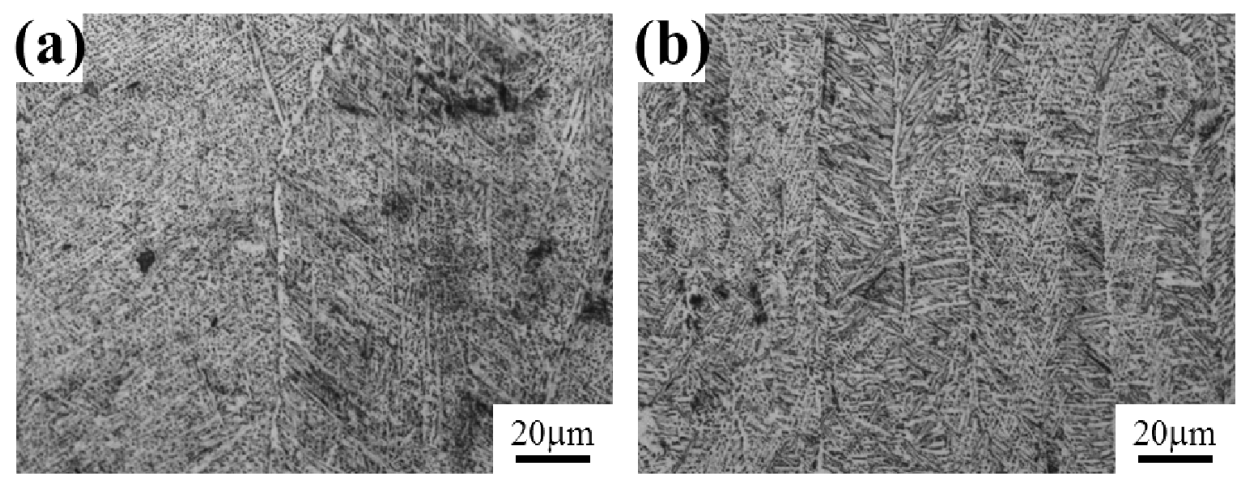

Fig. 4 Optical microsopy of (a) bottom and (b) top specimens from the as-printed Ti-6Al-4V plate.

Fig. 5 shows the room temperature tensile stress-strain curves of the as-printed Ti-6Al-4V specimens. Similar to the commercial wrought materials, only a weak work hardening was observed. More than $17 \%$ plastic strain was obtained in both the bottom and top specimens. The Young's modulus $(118.8 \pm 7.8 \mathrm{GPa}$ for bottom specimen and $116.1 \pm 4.0 \mathrm{GPa}$ for top specimen) calculated from the stress-strain curve in the present study was comparable with the previous reports [6]. Fig. 6 shows the YS and UTS of as-printed Ti-6Al-4V specimens. Independent of build height, both the YS and UTS of the top and bottom specimens were comparable to the results reported by S.S. Al-Bermani et.al [9] and that of the wrought Ti-6Al-4V according to ASTM 1472-14 [17]. Moreover, both YS and UTS decreased with an increase in build height (Fig. 6) and this is due to the presence of coarser $\alpha$ phase lath width (Fig. 4). It was reported that the YS decreased with the increase of $\alpha$ phase lath width in Ti-6Al-4V alloys [9]. On the other hand, the elongation exhibited a slight increase, from 17.9 $\pm 0.7 \%$ to $18.8 \pm 2.5 \%$ with the increase in build height. These values were higher than that of the wrought specimen (ASTM 1472-14, 10\%) [17]. Fig. 7 shows the fracture surfaces of bottom and top specimens. They all exhibited ductile fracture features. Small dimples and tear ridges were also observed, indicating good ductility in both sets of specimens.

\section{Summary}

The microstructure evolution and mechanical properties variation of big-sized Ti-6Al-4V plate $(6 \mathrm{~mm} \times 180 \mathrm{~mm} \times 372 \mathrm{~mm})$ were investigated using the XRD, $\mathrm{OM}, \mathrm{SEM}$ and tensile test.

(1) Only $\alpha$ phase and a relatively small fraction of $\beta$ phase were detected in the as-printed specimens. The $\alpha$ phase lath width increased with an increase of build height.

(2) Tensile properties exhibited a variation along the build height. With the increase of build height, the YS and UTS of the specimens decreased. This is attributed to the increase of $\alpha$ lath width due to the different thermal histories along the build height.

(3) The YS and UTS of both bottom and top specimens were comparable to that of the wrought specimens (ASTM 1472-14) and the elongation of both sets of specimens was higher than that of the wrought specimens (ASTM 1472-14).

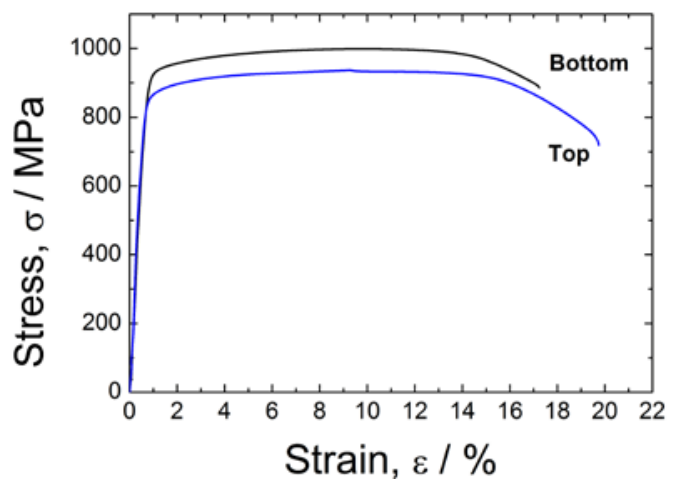

Fig. 5 Stress-strain curves of as-printed Ti-6Al-4V plate.

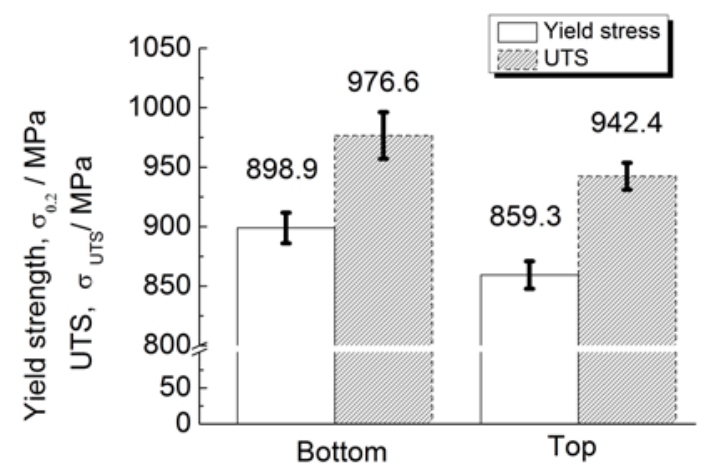

Fig. 6 Yield strength and ultimate tensile strength of as-printed Ti-6Al-4V plate. 

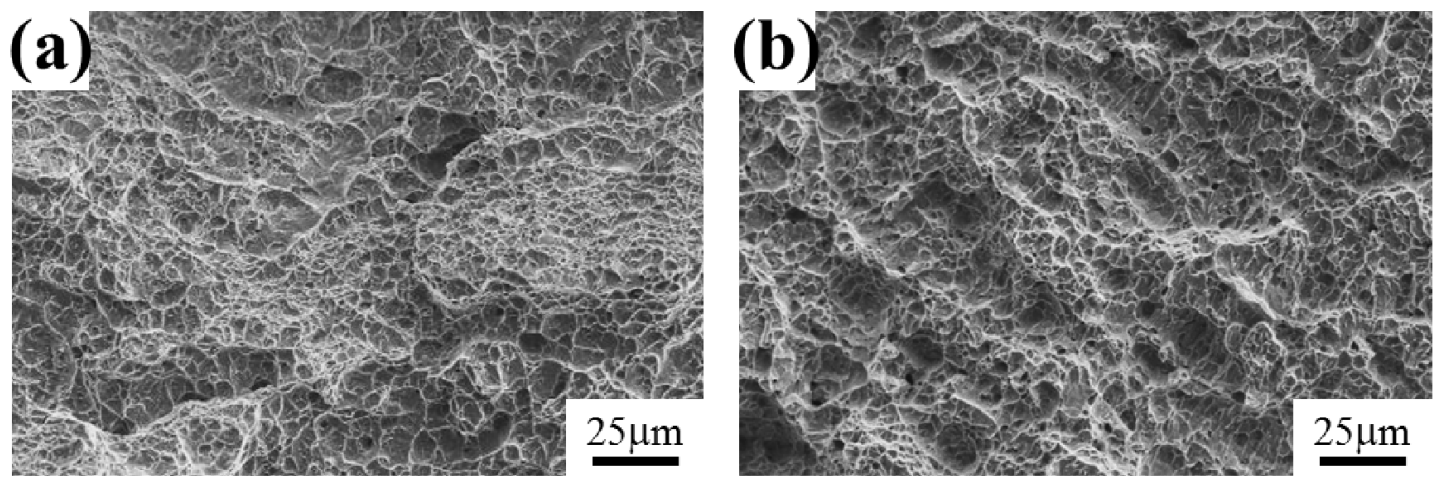

Fig. 7 Fracture surfaces of (a) bottom and (b) top specimens of as-printed Ti-6Al-4V plate.

\section{References}

1. Y. Zhai, D.A. Lados, J.L. LaGoy, JOM 66 (2014) 808.

2. S. Guan, L. Wu, P. Wang, Materials Science and Engineering: A 499 (2009) 187.

3. P. Wang, S. Zhu, L. Wang, L. Wu, S. Guan, Journal of Magnesium and Alloys 3 (2015) 70.

4. L. Greenemeier, Scientific American 308 (2013) 44.

5. H. Lipson, M. Kurman, Fabricated: The new world of 3D printing, John Wiley \& Sons, 2013.

6. L. Murr, E. Esquivel, S. Quinones, S. Gaytan, M. Lopez, E. Martinez, F. Medina, D. Hernandez, E. Martinez, J. Martinez, Materials Characterization 60 (2009) 96.

7. N. Ikeo, T. Ishimoto, T. Nakano, Journal of Alloys and Compounds 639 (2015) 336.

8. S.-H. Sun, Y. Koizumi, S. Kurosu, Y.-P. Li, A. Chiba, Acta Materialia 86 (2015) 305.
9. S. Al-Bermani, M. Blackmore, W. Zhang, I. Todd, Metallurgical and Materials Transactions A 41 (2010) 3422.

10. Y. Kok, X. Tan, S.B. Tor, C.K. Chua, Virtual and Physical Prototyping 10 (2015) 13.

11. [P. Prabhakar, W. Sames, R. Dehoff, S. Babu, Additive Manufacturing (2015).

12. N. Hrabe, T. Quinn, Materials Science and Engineering: A 573 (2013) 271

13. N. Hrabe, T. Quinn, Materials Science and Engineering: A 573 (2013) 264.

14. P. Wang, Y. Feng, F. Liu, L. Wu, S. Guan, Materials Science and Engineering: C 51 (2015) 148.

15. W. Pan, M. Todai, T. Nakano, Materials Transactions 54 (2013) 156.

16. S.H. Mok, G. Bi, J. Folkes, I. Pashby, J. Segal, Surface and Coatings Technology 202 (2008) 4613.

17. A. International, in, ASTM International, West Conshohocken, PA, 2014. 